\title{
Can Accessible Digital Formats Improve Reading Skills, Habits and Educational Level for Dyslectic Youngsters?
}

\author{
Simon Moe and Michael Wright \\ Nota, Danish National Library for Persons with Print Disabilities, Copenhagen, Denmark \\ \{sme, mwr $@$ nota.nu
}

\begin{abstract}
Dyslexic children face significant barriers when reading printed text. It has been well documented that subsequent lower reading frequency impacts the ability to read, vocabulary and the desire to go to school, causing a negative spiral. Finally, poor reading skills contribute to a significantly lower level of education than for the rest of the population. In 2010 Nota conducted a national study of dyslexic children's reading frequency, the use of hybrid audio and welfare. 500 children were interviewed in a telephone survey for half an hour. Further interviews were also conducted with 200 randomly selected children. The study supports a positive correlation between dyslexic children's access to and use of accessible digital formats and their reading habits, satisfaction with school and ambitions for further education.
\end{abstract}

Keywords: Audiobooks, Dyslexia, Print Disabilities, Daisy.

\section{Introduction}

According to the PISA investigations from 2009, $15 \%$ of a year group in Denmark are functionally weak readers and just under 5\% are really good readers (Læsning i PISA, 2009). The effort to raise the very weakest readers' learning environment and reading skills is a key challenge if changes are to be made in these conditions. However, the opportunities to compensate for finding it difficult to read - alternative access to literacy - are equally as important.

In order to be registered with Nota, one must produce written documentation signed by a professional or institution, which documents dyslexia or a similar level of severe reading difficulties. At Nota we are currently seeing a surprisingly large increase in registration of children and adolescents with dyslexia. Supposedly this development is due to a combined effect of stronger political focus on the subject, recent streamlining of the municipal handling of the issue and improvement in the services delivered by Nota as well as stronger communication efforts. In 2013 there are 6,565 dyslexic users in the age group 12-16 years old. In a few years it has thus become one of Nota's largest isolated user groups and at the same time a number, which is expected to correspond to about $50 \%$ of the total dyslexic population for that age group (Cf. table 1, chapter 3).

In order to better meet the wishes of this group and to better support and guide these children and adolescents in joint efforts to acquire knowledge and contribute to society; Nota took the initiative to investigate this group more closely. 
This report focuses on the part of the investigation's results, which concern the relationship between using audio books on a daily basis, and how one perceives being happy and manages at school. Here the investigation pointed out a statistically significant correlation. With more certain knowledge about impact and applicability, hybrid accessible media can ease the way and strengthen resolve through the education system.

\section{Review of Literature}

There are several areas where hybrid audio books are thought to have a beneficial effect on poor readers. Within reading research a distinction is usually made between two equally crucial processes, which together constitute the basis for reading, namely decoding and speech perception (i.e. Elbro, 2007). Decoding is the unique process of recognising words and letters; speech perception is a part of the ordinary linguistic generation of meaning. It thus makes sense to investigate a research-related justification of whether hybrid audio books can support these processes separately or as a whole.

In addition to these two processes it is necessarily a prerequisite that one is motivated to read and practises reading intensively. Therefore well being and reading frequency as well as how often the individual is engaged in reading are also important parameters for the student's success.

\subsection{Speech Perception}

Earlier studies suggest that audio books as compensation and as a supplement to printed text have a positive effect on speech perception for challenged readers.

A research project undertaken at J. Hopkins University in 2003, compared 67 challenged readers in two experimental groups and a control group and showed an increase of $38 \%$ in reading score for speech perception, for those students who use audio books accompanied by text. The study concludes that "it is noteworthy that the use of audio text had a significant effect on secondary level content acquisition" (Boyle et. Al., 2003).

\subsection{Decoding}

The hybrid audio books, which this project is about, are characterised by the text and audio being presented synchronously to the reader. The reader also sees the words whilst they are being reading out loud. It is conceivable that this hybrid form of reading could have a positive impact in relation to improving the reader's decoding of words as well.

According to an American study from 2000 reading in combination with text and computer-assisted recitation has an effect on the later unaided word reading, nonword reading and phonological awareness. 
In the study several different forms of recitation are to be compared - both when the computer reads out segments of words and whole words for the reader. In both cases the study concludes that there is a significant positive effect on the reader's ability to decode, concluding "Computer-speech support for whole words appears as helpful as segmented support in the speech- supported reading in context." (Wise et al., 2000).

There is a basic difference in the form of reading that was investigated in this study and the way Nota's readers follow the text whilst they are listening. For one thing Nota's books are read aloud by a human being - not a computer - and for another the words are only marked out at sentence level. Therefore closer studies of this form of reading will be needed in order to be able to conclude whether it has a significant impact on the reader's decoding competence.

In addition the frequency of reading - and particularly reading which gives rise to understanding and learning - is crucial to the student's automation "There is only one route to automation of a skill: practice". (Elbro, 2008) A significantly higher reading frequency will in itself, strengthen the student's decoding.

\subsection{Well-Being}

By lowering the threshold in order to reach the textual content, audio books can have a great bearing on the student's well-being and reading frequency. In a research project from 2009 Italian researchers investigated the combination of the audio books' effect on reading abilities with the impact on psycho-social factors and wellbeing. They conclude that audio books in lessons for 11-16 year old teenagers who had been tested for dyslexia had a significantly positive effect on the students' results, motivation and involvement.

"After 5 months of experimental training, the experimental group showed a significant improvement in reading accuracy, with reduced unease and emotionalbehavioural disorders, as well as an improvement in school performance and a greater motivation and involvement in school activities." Anna Milani Et al. (2009)

\section{Method}

This report has been prepared on the basis of an investigation that Nota have carried out in collaboration with the analysis company Epinion. The most important results take as their starting point a telephone survey undertaken by 497 of Nota's members in the age group 12 to 16 years old. For comparison 200 randomly chosen children and adolescents in the same age group have answered the same questions. In the report the two groups are differentiated by calling Nota's user group "the user group" and the 200 randomly chosen are called "the comparison group". 


\subsection{About the Random Sample of Nota's Users and the Population with Dyslexia}

According to Videnscenter for handicap, hjælpemidler and socialpsykiatri (VIHS) (the Danish research centre for the disabled, assistive technology and social psychiatry) $5-7 \%$ of the population is dyslexic, whilst foreign investigations estimate that $2-5 \%$ of the population are dyslexic according to where one sets the limit for dyslexia (VIHS, 2013). If one assumes that $4 \%$ of the Danish population suffers from dyslexia, this figure corresponds to the registered number of $47 \%$ of the dyslexic population in the age group.

It is against Danish legislation to take registers of a disability such as dyslexia. Therefore there is no access to representative random samples of the total population of dyslexic. Nationally, representative investigations of this population have not been undertaken either.

Table 1. 6,565 adolescents with dyslexia are today registered with Nota, corresponding to $47 \%$ of the assumed total population of dyslexic in the age group 12-16 years old

\begin{tabular}{|l|l|l|}
\hline DK Youth between 12 and 16 & Est. Dyslectics & Enrolled at Nota \\
\hline 344.103 & $13.764(4 \%)$ & 6.565 \\
\hline
\end{tabular}

This investigation is representative with regard to Nota's members and consequently therefore representative of approximately $47 \%$ of the $12-16$ year old dyslexics in Denmark. Some initial assumptions about the user group's divergence from the total may, however, be made:

The dyslexic youngsters in Nota's user group are both discovered and diagnosed as such and thus - presumably - better aided than dyslexic youngsters in general who may or may not have been identified as having severe reading difficulties.

Regardless of whether it is the individual themselves, parents or a teacher who has registered them - enrolment is an indication of an active movement in the direction of better learning environment support etc. than for the average population.

There is reason to surmise that the degree of dyslexia is the same for Nota's users as for other dyslexics in the population, but overall it is assessed that the learning environment as well as support and well-being in a school and family context etc. is stronger. This particularly applies to the most active percentage (with regard to the use of Nota's products) the 12-16 year old users.

\section{Results}

\subsection{Hybrid Reading}

$66 \%$ of the respondents always use text to assist the audio books. Either in an ordinary book or on a computer screen. 
Table 2. Do you use text to assist reading, when you listen to audiobooks from Nota?

\begin{tabular}{|l|r|}
\hline \multicolumn{1}{|c|}{ User group } & \multicolumn{1}{|c|}{ Total } \\
\hline Yes, in an ordinary book & $37 \%$ \\
\hline Yes, on a computer screen & $18 \%$ \\
\hline Yes, either in an ordinary book or on a computer screen & $11 \%$ \\
\hline No & $33 \%$ \\
\hline
\end{tabular}

\subsection{Positive Effect of Audio Books}

Just under a third of the user group listen to audio books daily or weekly; every third person never listens to an audio book. Thus audio books are for a large percentage of these children and adolescents an absolutely central way of reading - and thus gaining knowledge and experiences. By comparison only 3\% of the comparison group listen to audio books weekly or more often. The comparison group is a representative random sample, so the $3 \%$ is presumably comprised of dyslexic/children and adolescents with dyslexia (c.f. Introduction).

Table 3. Do you ever listen to an audio book?

\begin{tabular}{|l|r|r|}
\hline & Comparison group & User group \\
\hline Daily & $1 \%$ & $11 \%$ \\
\hline Weekly & $2 \%$ & $21 \%$ \\
\hline Monthly & $3 \%$ & $22 \%$ \\
\hline Rarer than once a month & $10 \%$ & $18 \%$ \\
\hline No & $82 \%$ & $28 \%$ \\
\hline I don't know what it is & $1 \%$ & $0 \%$ \\
\hline Total & $100 \%$ & $100 \%$ \\
\hline
\end{tabular}

Every other person in the user group uses or has used schoolbooks in the form of audio books. It is primarily a remedial teacher or another teacher who is responsible for purchasing them when this happens. There is no legislation or other scheme which ensures students access to audio books or other alternative school materials in secondary schools in Denmark. 
Table 4. Do you have or have you had any of your school books in the form of audio books?

\begin{tabular}{|l|c|c|c|c|c|c|}
\hline User group & $\mathbf{1 2}$ & $\mathbf{1 3}$ & $\mathbf{1 4}$ & $\mathbf{1 5}$ & $\mathbf{1 6}$ & Total \\
\hline Yes & $47 \%$ & $51 \%$ & $61 \%$ & $57 \%$ & $41 \%$ & $51 \%$ \\
\hline No & $53 \%$ & $49 \%$ & $39 \%$ & $40 \%$ & $56 \%$ & $48 \%$ \\
\hline Don't know & $0 \%$ & $0 \%$ & $0 \%$ & $3 \%$ & $2 \%$ & $1 \%$ \\
\hline Total & $100 \%$ & $100 \%$ & $100 \%$ & $100 \%$ & $100 \%$ & $100 \%$ \\
\hline
\end{tabular}

The investigation documents that there is a positive correlation between the use of audio books, homework habits, reading habits and well being in school.

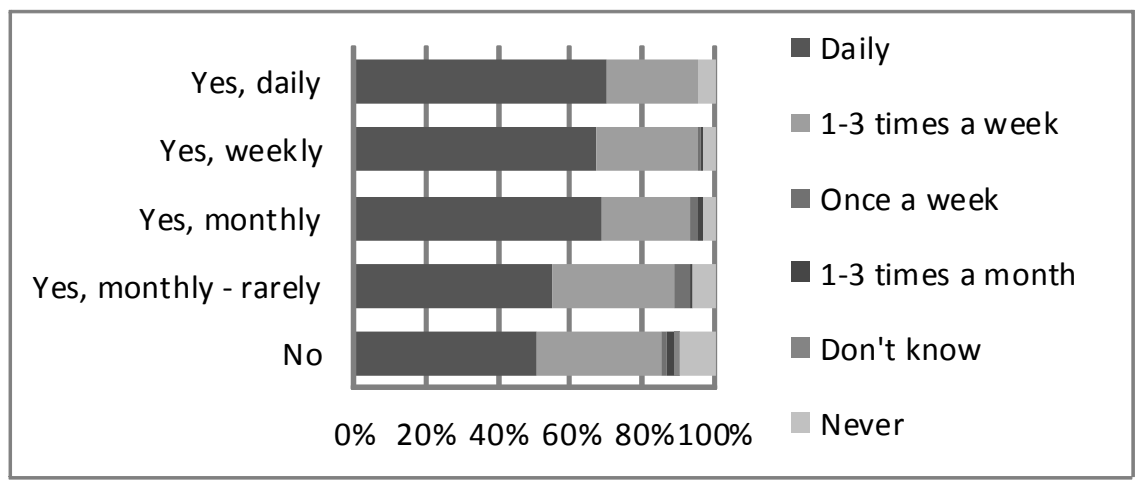

Fig. 1. Use of audio books I "How often do you do homework?" No":n=137. "Yes, but less than once a month":n=89. "Yes, every month":n=89. "Yes, every week":n=106. "Yes, every day": $n=55$. Total: $n=497$. Statistically significant with a level of significance of $5 \%$.

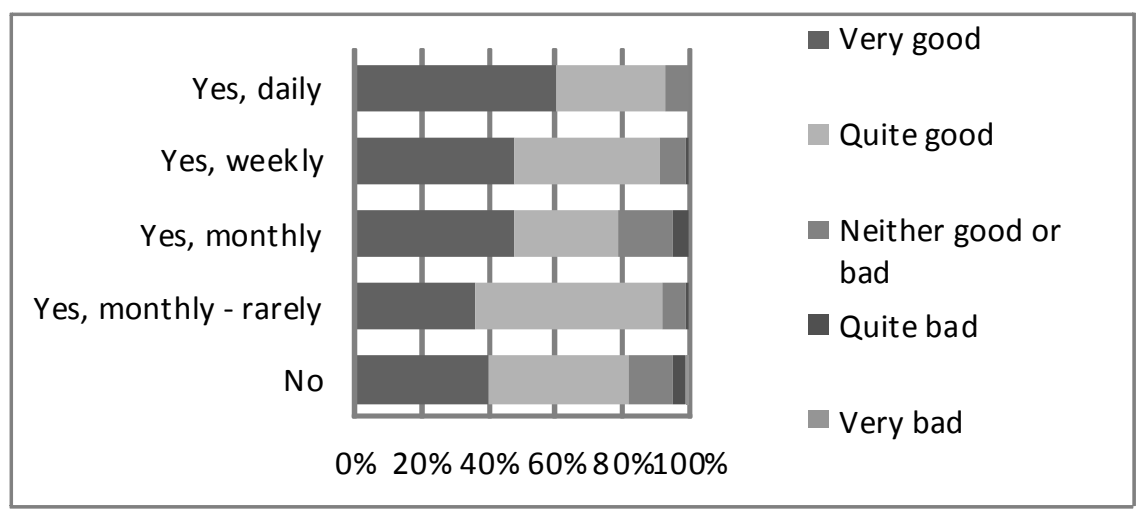

Fig. 2. Use of audio books I "On the whole how do you feel about going to school?" Same number as in figure 1 . Statistically significant with a level of significance of $1 \%$. 


\subsection{Reading and Homework}

On the whole $2 \%$ of the members consider that they read better than the average for 12-16 year olds. $80 \%$ responded that they would like to use their holidays or spare time to become better readers.

The user group resemble the comparison group with regard to time spent on homework and time spent reading. $90 \%$ of the user group does homework daily or two to three times a week, the corresponding figure for the comparison group is $92 \%$. $77 \%$ of the user group spend half an hour or more reading each day, this applies to $85 \%$ of the comparison group. Also in relation to media habits and consumption the two groups resemble each other, even though there are several places where the adolescents in the user group stand out positively in relation to a more comprehensive use of media and technology.

\subsection{Technology and Assistive Technology}

$99 \%$ of Nota's users have access to a PC that they can use. Only $1 \%$ has neither an IT rucksack (An IT rucksack is a support computer handed out by the school) nor PC. It is significantly more common for the dyslexic adolescents to have a computer with them daily at school (46\%) than in the comparison group (17\%).

\section{User group}

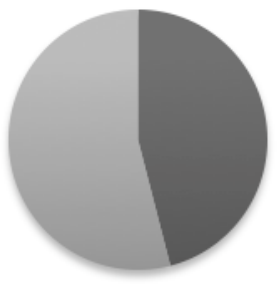

Comparison

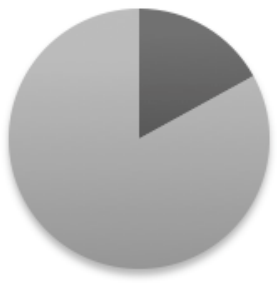

Daily

Rarely never

Fig. 3. Estimated percentages of those who have either a computer or/and IT rucksack with them daily at school. Every other person from the user group has a portable computer or IT rucksack with them daily at school. This only applies to a fifth of the comparison group.

\subsection{Schooling and Well-Being}

$60 \%$ have changed school one or more times, which is $20 \%$ more than the comparison group. The most frequent reason for a change of school is dyslexia. Thus a fifth of the user group have experienced changing school as a consequence of reading difficulties.

When asked about well-being Nota's members, however, generally indicate that they feel good at school and in the lessons, despite reading difficulties and the change 
in school. 98\% reply that they always receive the reading help from home or elsewhere, when needed. $94 \%$ also indicate that they receive help and instructions for the assistive technology that they need. Conversely the adolescents in the user group do not generally know a lot about what help and offers they have a right to (46\%).

\subsection{Education Plans}

$15 \%$ of the user group plans to go on to an upper secondary education after secondary school. In addition $7 \%$ plan on an upper secondary education after a stay at a lower secondary boarding school. $28 \%$ plan to continue straight away with a vocational education, whilst a further $12 \%$ will plan such things after a stay at a lower secondary boarding school.

By comparison $46 \%$ of the comparison group are planning to continue with an upper secondary education after secondary school, whilst only $8 \%$ plan on a vocational education. The reading difficulties also have an apparent and crucial effect on the adolescents' plans for the future.

Table 5. Overall - answers to the question: Have you plans to go on to one of the following courses when you have finished at secondary school/primary school

\begin{tabular}{|l|r|r|}
\hline Educations plans & User group & Comparison group \\
\hline Lower secondary boarding school & $31 \%$ & $14 \%$ \\
\hline $\begin{array}{l}\text { Upper secondary school, Higher } \\
\text { Preparatory Examination Course (HF), } \\
\text { upper secondary level evening school }\end{array}$ & $9 \%$ & $40 \%$ \\
\hline $\begin{array}{l}\text { Business School (higher commercial } \\
\text { examination (HHX) or Higher } \\
\text { Technical Examination (HTX)) }\end{array}$ & $6 \%$ & $6 \%$ \\
\hline Vocational education & $28 \%$ & $8 \%$ \\
\hline Don't know & $19 \%$ & $23 \%$ \\
\hline $\begin{array}{l}\text { Other/possibly study a subject in more } \\
\text { detail }\end{array}$ & $7 \%$ & $10 \%$ \\
\hline Total & $100 \%$ & $100 \%$ \\
\hline
\end{tabular}

\section{$5 \quad$ Discussion and Future Steps}

Before Nota's investigation we did not anticipate that adolescents with dyslexia used audio books to support their schooling and reading skills to the great extent shown. Follow up qualitative investigations suggest that the audio books are regarded more as "homework" than "experiences" amongst the adolescents - and this function is 
supported by both the teachers and parents around them (Jensen, 2012). Many parents ensure that the adolescents have a printed copy of the book and keep up with it all the time.

$66 \%$ of the respondents always use text to assist listening to audiobooks. This substantiates that the dyslexics themselves regard the reading as reading training rather than fun. The positive correlation between use of audiobooks, well-being in school, reading frequency and time spent on homework combined with the high amount of hybrid reading, suggest that hybrid audio books are in many ways an obvious candidate for a standard format for accessible schoolbooks for people with reading difficulties. The technology presents many new opportunities to support such a generalisation and new opportunities within, among other things, speech synthesis and synchronisation make it less costly than previously.

However, there is still qualitative didactic research missing in precisely how the formats shall be constructed. In what situations is speech synthesis adequate? What significance has typography, formatting and media for the various end users and contexts? What significance has marking out at the word and sentence level etc.?

We hope that this and other reports which show a positive effect of digital hybrid formats, will lead to increased knowledge and exploration about the formats' significance and potential for people with reading difficulties. We will then move in the direction of parity between availability to literacy and experiences in the future.

\section{References}

1. Aller, E.: Læsning i PISA, UVM.dk (2009), http://uvm.dk/Uddannelser-ogdagtilbud/Folkeskolen/De-nationale-test-og-evaluering/ Internationale-evalueringer/PISA/PISA-2009/ PISA-2009-1aesning (accessed February 27, 2013)

2. Boyle, E.A., Rosenberg, M.S., Connelly, V.J., Washburn, S.G., Brinckerhoff, L.C., Banerjee, M.: Effects of audio texts on the acquisition of secondary-level content by students with mild disabilities. Learning Disability Quarterly 26(3), 203-214 (2003)

3. Elbro, C.: Læsevanskeligheder, 2.imp, 1st edn., p. 39. Gyldendalske Boghandel, Nordisk Forlag A/S, København $(2007,2008)$

4. Elbro, C.: Læsning og Læseundervisning, 2.imp, 2nd edn., p. 164. Gyldendalske Boghandel, Nordisk Forlag A/S, København $(2001,2008)$

5. Jensen, B.W.: p. 14. Nota (2012) http: / /www . nota.nu/ kvalitativt-studie-af-sammenhaenge-i-uddannelsessystemet (accessed March 1, 2013)

6. Lyytinen \& Erskine.: Early Identification and Prevention of Reading Problems,Child Research Centre \& Department of Psychology, University of Jyväskylä, Finland (2006), http:/ /www. child-encyclopedia.com/documents / LyYtinen-ErskineANGxp.pdf (accessed February 27, 2013)

7. Milani, A., Lorusso, M.L., Molteni, M.: The Effects of Audiobooks on the Psychosocial Adjustment of Pre-adolescents and Adolescents with Dyslexia, p. 87. John Wiley \& Sons, Ltd. (2009) 
8. Nota, Epinion.: Auxiliary aids and access to learning for children and young people with dyslexia/severe reading difficulties, Nota, pp. 18, 19, 29, 30, 31, 32, 39, 54, 56, 90 (2010), http: / /www. nota.nu/sites/default/files/ English_version_of_survey.pdf (English translation)

9. VIHS, Om Ordblindhed, http: //socialstyrelsen.dk/handicap/ordblindhed/ om-ordblindhed (accessed March 1, 2013)

10. Wise, B.W., Ring, J., Olson, R.K., et al.: Individual Differences in Gains from ComputerAssisted Remedial Reading. Journal of Experimental Child Psychology 77, 197-235 (2000) 